\title{
Population-Level Reach of Cardiovascular Disease Prevention Interventions in a Rural Community: Findings from the Heart of New Ulm Project
}

\author{
Abbey C. Sidebottom, MPH, PhD, ${ }^{1}$ Gretchen Benson, BA, ${ }^{2}$ Marc Vacquier, MS, ${ }^{1}$ Raquel Pereira, MS, \\ Joy Hayes, MS, ${ }^{2}$ Peter Boersma, MPH, ${ }^{2}$ Jackie L. Boucher, MS, ${ }^{3}$ Rebecca Lindberg, MPH, ${ }^{2}$ \\ Barbara Pribyl, BA, ${ }^{4}$ and Jeffrey J. VanWormer, $\mathrm{PhD}^{5}$
}

\begin{abstract}
This study examines participation by residents of a rural community in programs implemented as part of The Heart of New Ulm (HONU) Project, a population-based cardiovascular disease (CVD) prevention initiative. The study compares participation rates for the various interventions to assess which were the most engaging in the priority community and identifies factors that differentiate participants vs. nonparticipants. Participation data were merged with electronic health record (EHR) data representing the larger community population to enable an analysis of participation in the context of the entire community. HONU individual-level interventions engaged $44 \%$ of adult residents in the community. Participation ranked as follows: (1) heart health screenings (37\% of adult residents), (2) a year-long community weight loss intervention (12\% of adult residents), (3) community health challenges (10\% of adult residents), and (4) a phone coaching program for invited high CVD-risk residents (enrolled 6\% of adult residents). Interventions that yielded the highest engagement were those that had significant staffing and recruited participants over several months, often with many opportunities to participate or register. Compared to nonparticipants, HONU participants were significantly older and a higher proportion were female, married, overweight or obese, and had high cholesterol. Participants also had a lower prevalence of smoking and diabetes than nonparticipants. Findings indicate community-based CVD prevention initiatives can be successful in engaging a high proportion of adult community members. Partnering with local health care systems can allow for use of EHR data to identify eligible participants and evaluate reach and engagement of the priority population.
\end{abstract}

Keywords: program participation, community engagement, community-based, population, cardiovascular disease, prevention

\section{Introduction}

C ARDIOVASCULAR DISEASE (CVD) AND its associated risk factors are the principal drivers of mortality and health care costs in the United States. ${ }^{1}$ Prevalence of CVD is higher in rural communities and heart disease death rates (age adjusted) are $18 \%-20 \%$ higher for residents of rural counties than suburban residents. ${ }^{2,3}$

CVD is primarily attributable to 9 modifiable risk factors including lifestyle (ie, smoking, inadequate fruit and vegetable intake, alcohol consumption, physical inactivity), high-risk biometric values (ie, blood pressure, lipids, obesity, diabetes), and psychosocial factors. ${ }^{4}$ All of these modifiable risk factors are influenced by the social and built environment, as well as clinical management. ${ }^{5}$ Increased risk of CVD in rural communities is related to several factors: higher prevalence of risk factors such as smoking, obesity, low levels of physical activity $^{2}$; poor access to medical care ${ }^{6}$; social and environmental conditions that are less supportive of healthy lifestyle behaviors (ie, food deserts) ${ }^{7-9}$; and higher poverty. ${ }^{10}$

${ }^{1}$ Care Delivery Research, Allina Health, Minneapolis, Minnesota, USA.

${ }^{2}$ Population Health, Minneapolis Heart Institute Foundation, Minneapolis, Minnesota, USA.

${ }^{3}$ Children's HeartLink, Edina, Minnesota, USA.

${ }_{5}^{4}$ Barb Pribyl Communications, Forest Lake, Minnesota, USA.

${ }^{5}$ Center for Clinical Epidemiology and Population Health, Marshfield Clinic Research Institute, Marshfield, Wisconsin, USA.

(c) Abbey C. Sidebottom, et al. 2020; Published by Mary Ann Liebert, Inc. This Open Access article is distributed under the terms of the Creative Commons Attribution Noncommercial License (http://creativecommons.org/licenses/by-nc/4.0/) which permits any noncommercial use, distribution, and reproduction in any medium, provided the original author(s) and the source are cited. 
To make an impact on the prevalence of CVD nationally, the American Heart Association (AHA) has identified the need for community-based CVD prevention programs that address multiple risk factors through interventions delivered in health care, worksite, and community settings, with a focus on educational, organizational, health care, policy, and environmental changes. ${ }^{11,12}$ Several studies documenting the prevalence of CVD risk factors in rural communities have called for interventions to address multiple risk factors through a social ecological framework. ${ }^{7,8,13}$

As part of the Triple and Quadruple Aims, health care organizations are increasingly expected to address the health of the populations they serve, with a focus on addressing risk factors outside the clinical domain such as behavioral and environmental factors. ${ }^{14,15}$ Partnerships between health care, government, and community organizations have the potential to address population health with interventions addressing social, environmental, and policy determinants of CVD risks. ${ }^{5,12,16-19}$ However, little evidence is available to guide implementation of such programs and how best to engage residents in CVD risk-reduction efforts. Residents of rural and other underserved communities have been underrepresented in clinical trials of behavioral modification, and face several barriers to participation in research and health improvement initiatives. ${ }^{20,21}$

The Heart of New Ulm (HONU) is a community-wide CVD prevention project implemented in a rural Minnesota community. ${ }^{22,23}$ After 6 years of HONU implementation, CVD risk was lower in a cohort of New Ulm residents relative to a cohort of residents from a rural comparison community served by the same health system (matched on baseline demographics and CVD risk markers), suggesting moderate effectiveness for the HONU project. ${ }^{24}$ In order to contribute to the development of CVD prevention interventions in rural communities, the aim of this study is to report on participation rates for the various individual-level HONU interventions in order to identify which types of interventions were most successful in terms of population engagement. A secondary goal is to identify factors that differentiate intervention participants from nonparticipants.

\section{Methods}

\section{Setting and intervention description}

Initiated in 2009, HONU is a community-based demonstration project aimed at reducing myocardial infarctions (MIs) and improving modifiable CVD risk factors in the rural community of New Ulm, MN. ${ }^{22,23}$ HONU is a collaborative partnership of the Minneapolis Heart Institute Foundation, Allina Health, and the community of New Ulm. Although HONU interventions are open to, and may impact, all adults in the community, the priority population is residents of the 56073 zip code ages $40-79$ years. ${ }^{25}$ This age group was selected because preliminary evaluations indicated they were most likely to experience incident MIs.

The priority zip code has a population of 16,759 , with $7855(47 \%)$ residents in the 40-79-year age range. The community is racially homogeneous at $98 \%$ white and $1 \%$ Hispanic. Health insurance levels are high, with an estimated $4 \%$ of residents lacking insurance. Among residents ages $\geq 25$ years, $22 \%$ have a bachelor's degree or higher. ${ }^{25}$ Health care in this community is provided primarily by 1 health system (Allina Health) that operates the New Ulm Medical Center (NUMC). Previous research suggests that electronic health record (EHR) data provide a reasonable assessment of the health of the HONU target community. ${ }^{26}$

HONU interventions, described in detail elsewhere, ${ }^{22,23,27-29}$ were designed to focus on major modifiable CVD risks. ${ }^{4}$ Evidence to date supports CVD risk factor improvement for individual interventions and the comprehensive package of interventions. ${ }^{24,28-31}$ Project priorities were identified from a community assessment that identified the most prevalent risk factors as overweight/obesity, metabolic syndrome, low fruit and vegetable consumption, and low use of preventive medication among those with elevated risk for CVD. ${ }^{23}$ Interventions were designed to fill gaps where other options did not exist in the community. Interventions were delivered through health care, worksite, and community settings.

The HONU model aligns with evidence-based strategies and AHA guidelines for improving cardiovascular health at the community level ${ }^{12}$ by bringing health care organizations, the public sector, community organizations, and employers together in partnership. These key stakeholders helped inform and implement a comprehensive set of interventions promoting optimal behaviors through a variety of settings across all levels of the social-ecological model (Figure 1). ${ }^{32}$ HONU interventions were developed by staff with approval and input from a community advisory team who represented diverse sectors of the community. Intervention development also incorporated a resident feedback process, such as focus groups or informational interviews, to ensure messaging and intervention components would resonate with the priority population.

Intervention strategies implemented at the policy, community, and organizational levels of the social-ecological model included tobacco-free workplace policies; programs, policies and physical road changes to create a safer and more supportive environment for residents to walk or bike; social marketing to promote physical activity or healthier food choices; food environment improvements in partnership with local restaurants, grocery stores, and convenience stores and promotion of the farmers market. Additionally, HONU built brand awareness by conducting a comprehensive communications and marketing strategy to increase visibility and awareness of HONU interventions, as well as to amplify key behavior messages in the community.

HONU offered 20 specific individual-level participation interventions to various segments of the community over the course of 6 years (2009-2014) with enrollment tracking (Table 1, Figure 2). The focus of this paper is to understand participation rates of individual-level programs. These include heart health screenings, ${ }^{23}$ community health challenges (6- to 8-week behavior change challenges implemented twice a year; one with a specific theme and one annual challenge called "Holiday Trimmings"), a year-long community-wide weight loss challenge, ${ }^{30}$ a primary prevention phone coaching program for residents at high risk for $\mathrm{CVD},{ }^{27,31}$ grocery store tours, cooking shows, and worksite behavior change interventions. Overall, most intervention offerings were available to all adult community residents. However, some interventions were marketed specifically to worksites or a specific segment of the population.

Given that the HONU project spans a 10 -year period, recruitment strategies evolved over the course of the project. These efforts also were dependent on intervention intensity 


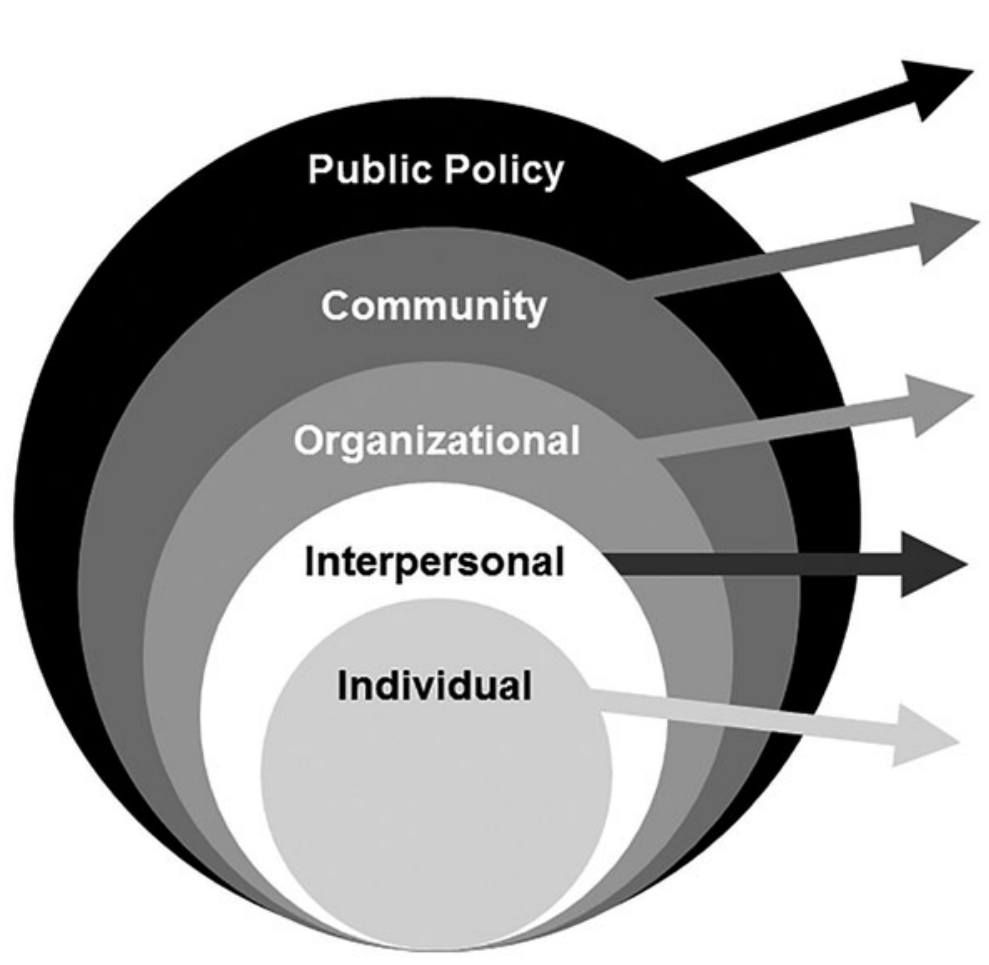

Promotion of city-wide policies to improve the built environment (i.e., Complete Streets Policy, Safe Routes to School engineering component)

Partnerships with restaurants, grocery stores, convenience stores, and farmers markets/ CSAs; community health summits; media; run/walk events; project communications

Worksite wellness programs and policy initiatives (e.g., healthy vending and smoking policies); education delivered to clinic and worksite leadership; NUMC Grand Rounds; heart health screenings conducted at worksites

Social marketing campaign; social media; small community events; Safe Routes to School (education, encouragement, enforcement and evaluation components)

Heart health screenings conducted in community; personalized phone coaching for high risk residents (HeartBeat Connections); community health challenges (focus on nutrition, physical activity and weight management); general education; heart and vascular prevention clinic

FIG. 1. Health of New Ulm initiatives in social-ecological model framework.

CSA, Community-Supported Agriculture; NUMC, New Ulm Medical Center.

or length and resources available for each specific program (eg, additional grant funding, employee availability). Table 1 documents the varied offerings, duration of participation, and intensity of recruitment efforts. Broadly, HONU conducted recruitment activities in residents' homes (eg, direct mail, newspaper ads and stories, cable TV cooking show), in their cars (eg, radio and billboard advertising), at work (eg, promotional flyers, emails), online (eg, website, social media, email communications), and throughout the community (eg, restaurants, grocery stores, farmers markets, convenience stores, schools, Chamber of Commerce). ${ }^{33}$

The first 6 years, the project's initial funding included $\$ 5,992,616$ from the Allina Health system. This funding primarily covered staff and the infrastructure to carry out the research. Additional funding mechanisms included private grant funding of $\$ 992,975$ to conduct the programs, as well as policy, systems and environment improvements. The project also received federal funding of $\$ 283,202$ and state funding of $\$ 5976$ to make improvements to the food and built environments. The project also received $\$ 31,450$ of individual philanthropy to support general operations. Given all funding streams, the project had, on average, $\$ 1.2$ million per year during the current study period to cover all research-associated expenses, interventions (not just individual level), and operations.

\section{Design, data collection, and measures}

This study utilizes a retrospective cohort design to assess project reach and engagement in the community. Data for this study come from the EHR and participation tracking databases. The use of these data for this study was approved by the Allina Institutional Review Board.

EHR data. NUMC is the only hospital and clinic in the HONU community; thus nearly all of the community's residents are represented in the data. ${ }^{26,29}$ Data extracts selected for this study include data for adult residents of the HONU priority area who had been served by NUMC during the HONU baseline time period of 2008-2009. Data were selected for adult residents of the HONU zip code with at least 1 ambulatory face-to-face visit with NUMC during 2008-2009. Individuals were excluded if they did not provide consent for use of their EHR data in research or if they died during the extract time period.

Specific patient measures extracted from the EHR for this study include: sex, age (as of their first encounter in the extract period), race, ethnicity, and marital status. Health risk factors were the last documented value during the extract period, including smoking status, blood pressure, total cholesterol, low-density lipoprotein cholesterol (LDL-C), highdensity lipoprotein cholesterol (HDL-C), and height and weight to calculate body mass index (BMI). Visit diagnosis codes during the extract period were used to determine if the patient had a diagnosis of diabetes (type 1 or 2).

CVD risk factors were categorized based on health recommendations, with "at goal" levels defined as: blood pressure $<140 / 90 \mathrm{mmHg}$, total cholesterol $<200 \mathrm{mg} / \mathrm{dL}$, LDL-C $<130 \mathrm{mg} / \mathrm{dl}$, HDL-C $\geq 40 \mathrm{mg} / \mathrm{dL}$ for $\mathrm{men} / \geq 50 \mathrm{mg} / \mathrm{dL}$ for women, triglycerides $<150 \mathrm{mg} / \mathrm{dL}$. BMI was grouped into 3 categories: healthy weight $\left(<25 \mathrm{~kg} / \mathrm{m}^{2}\right)$, overweight $\left(25-29 \mathrm{~kg} / \mathrm{m}^{2}\right)$, and obese $\left(\geq 30 \mathrm{~kg} / \mathrm{m}^{2}\right)$. 


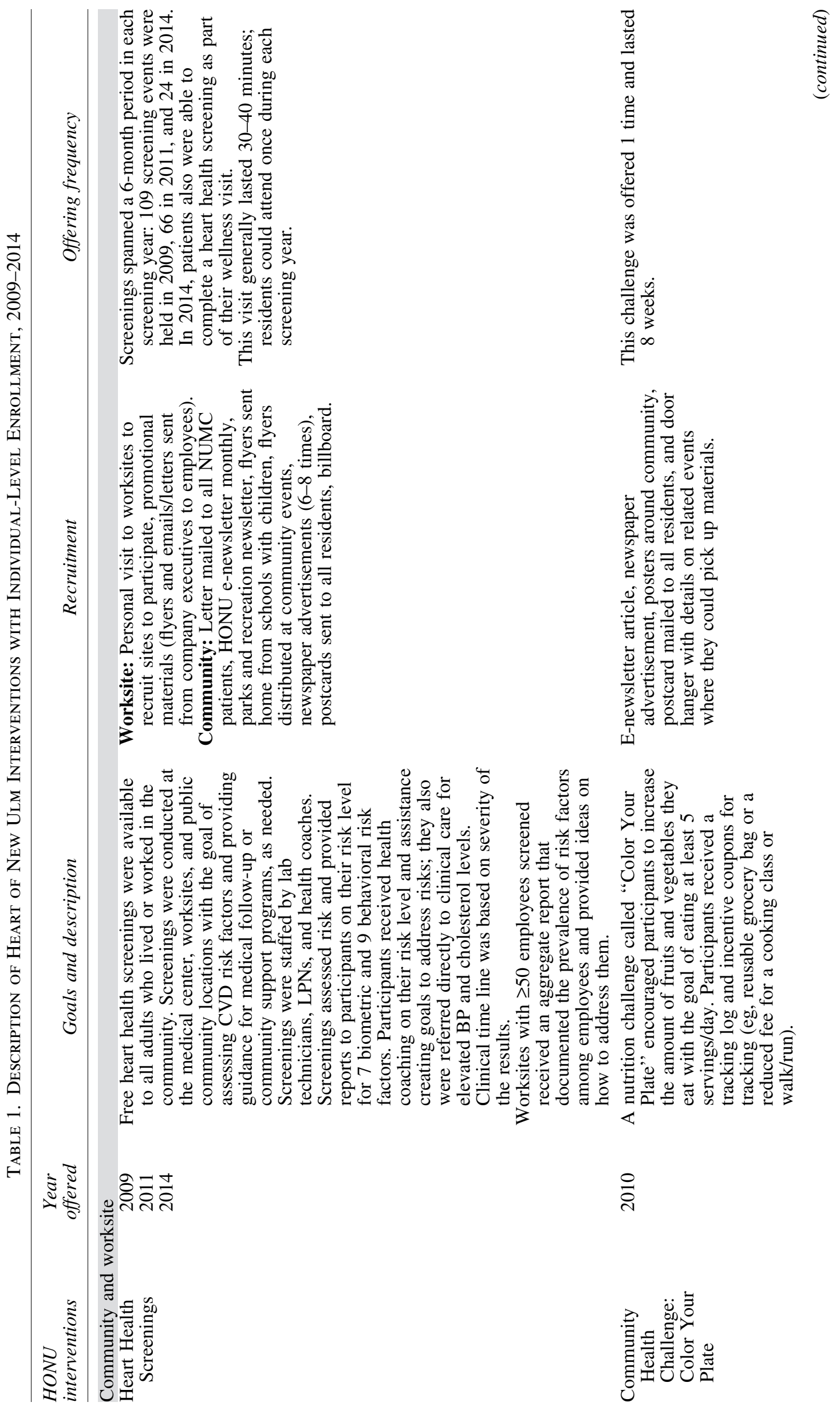




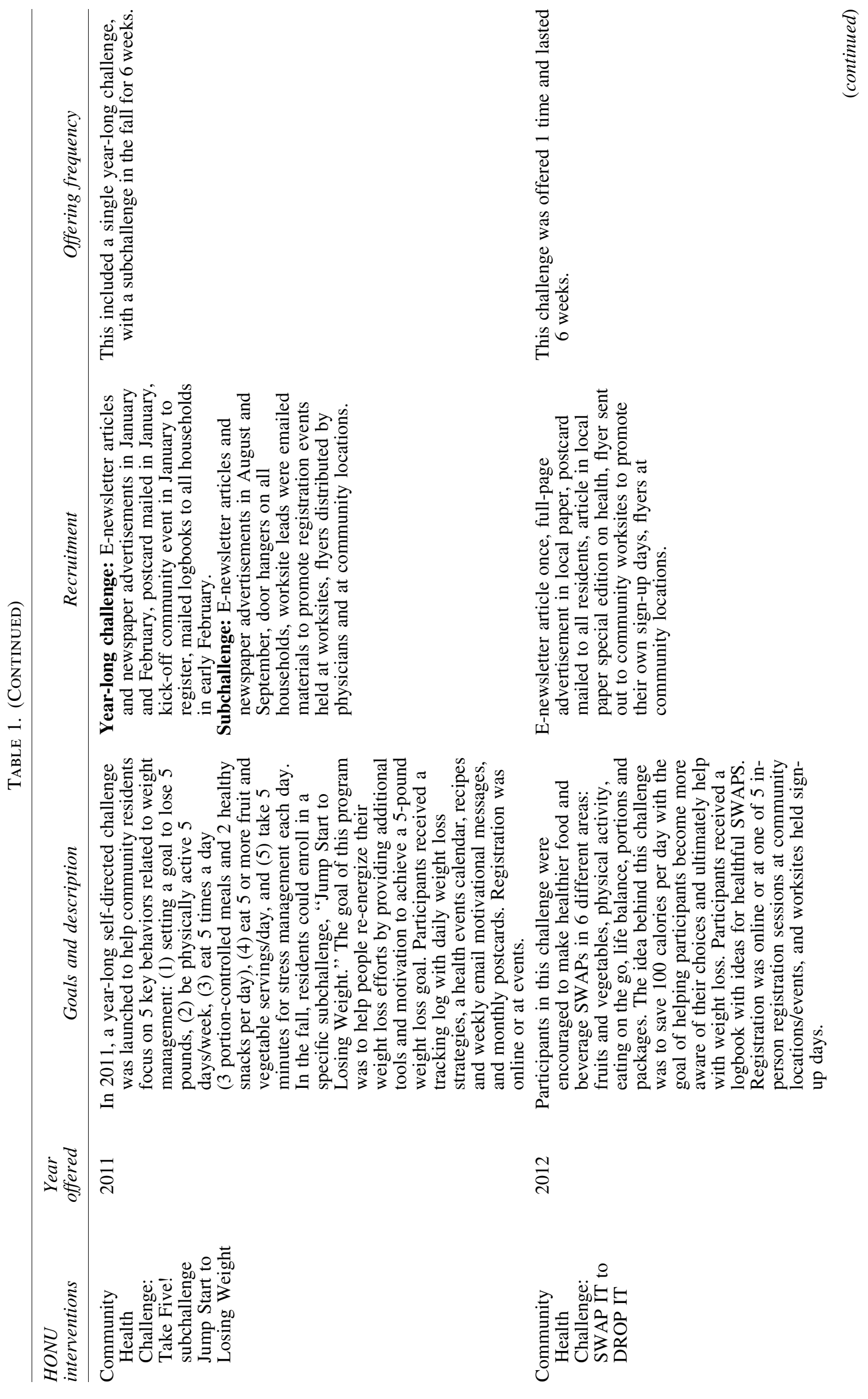




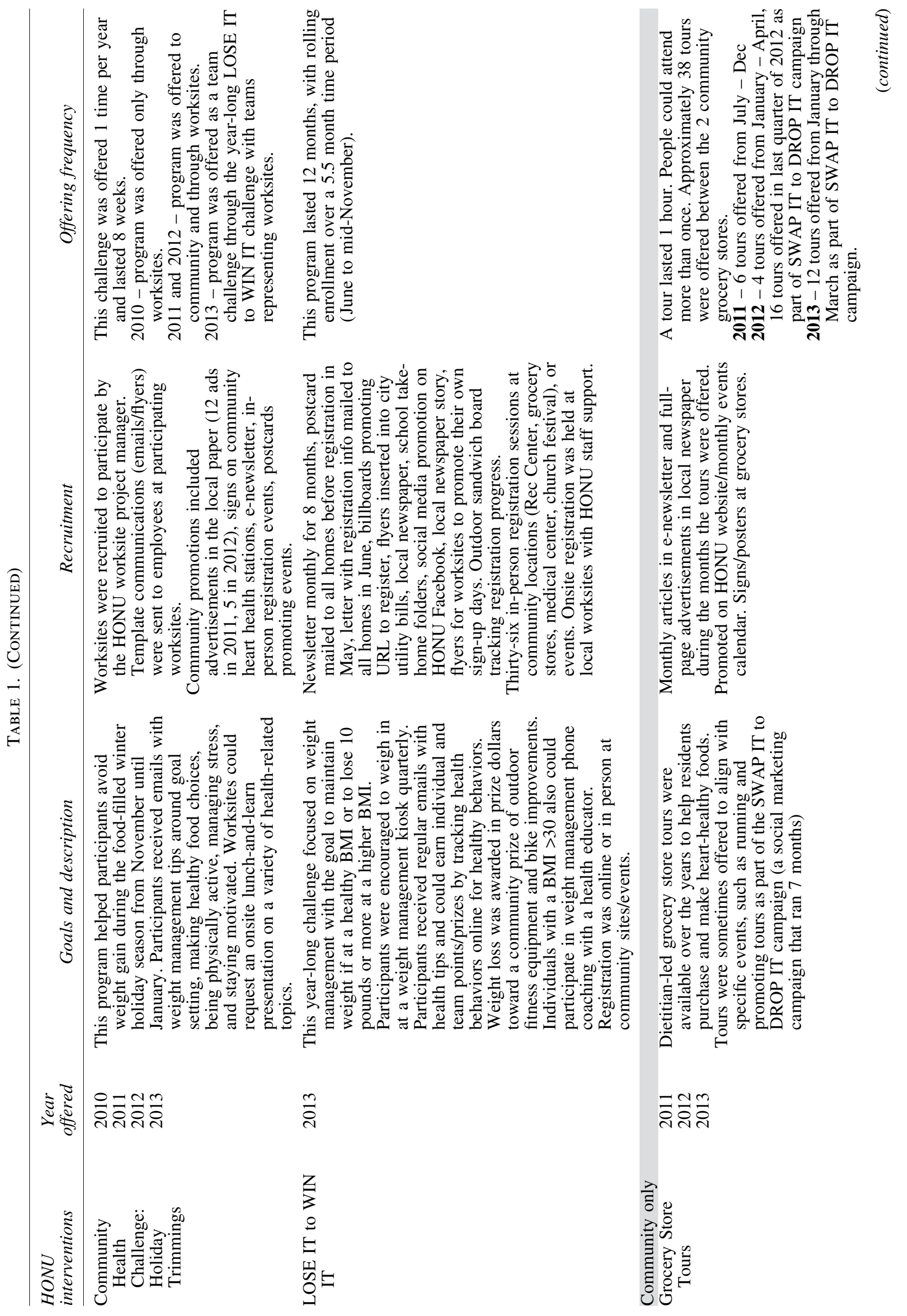




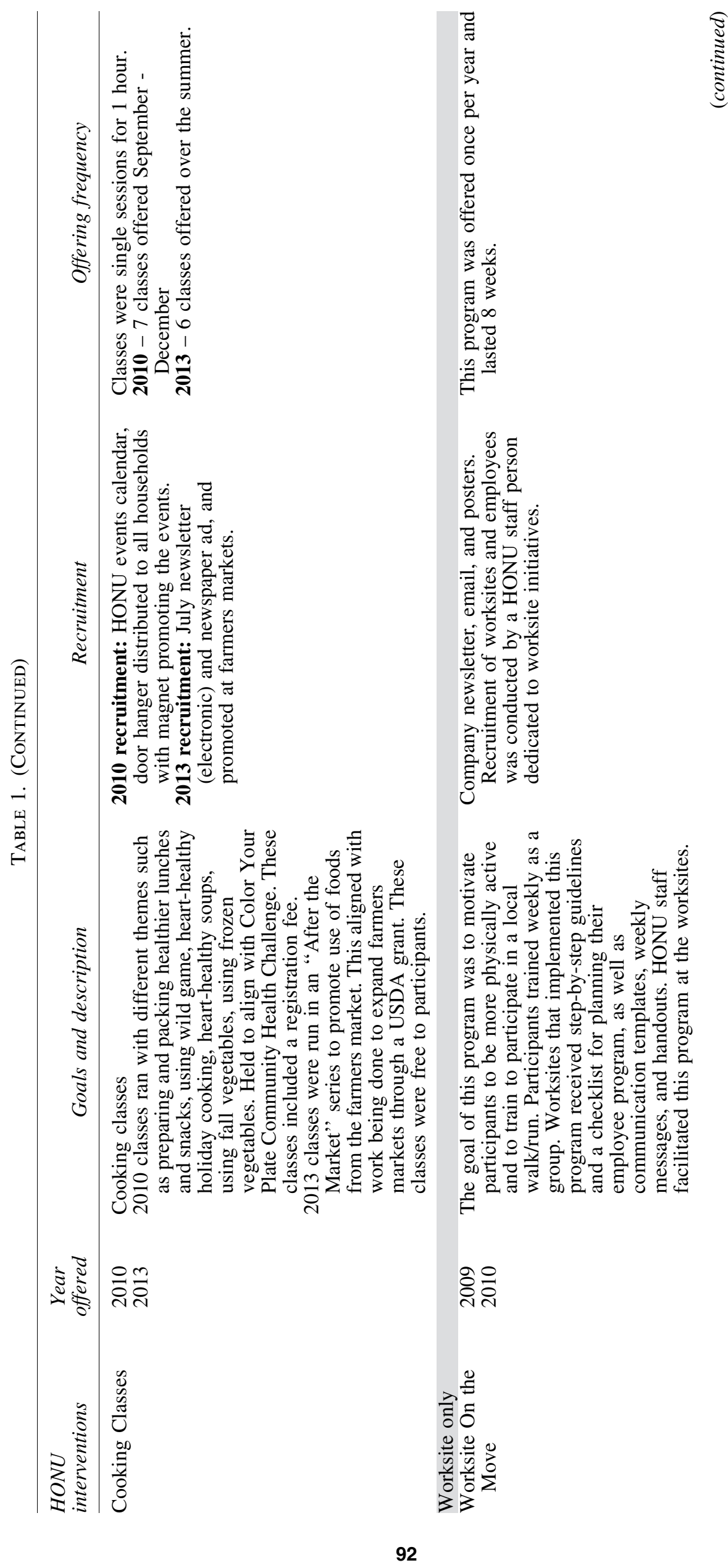









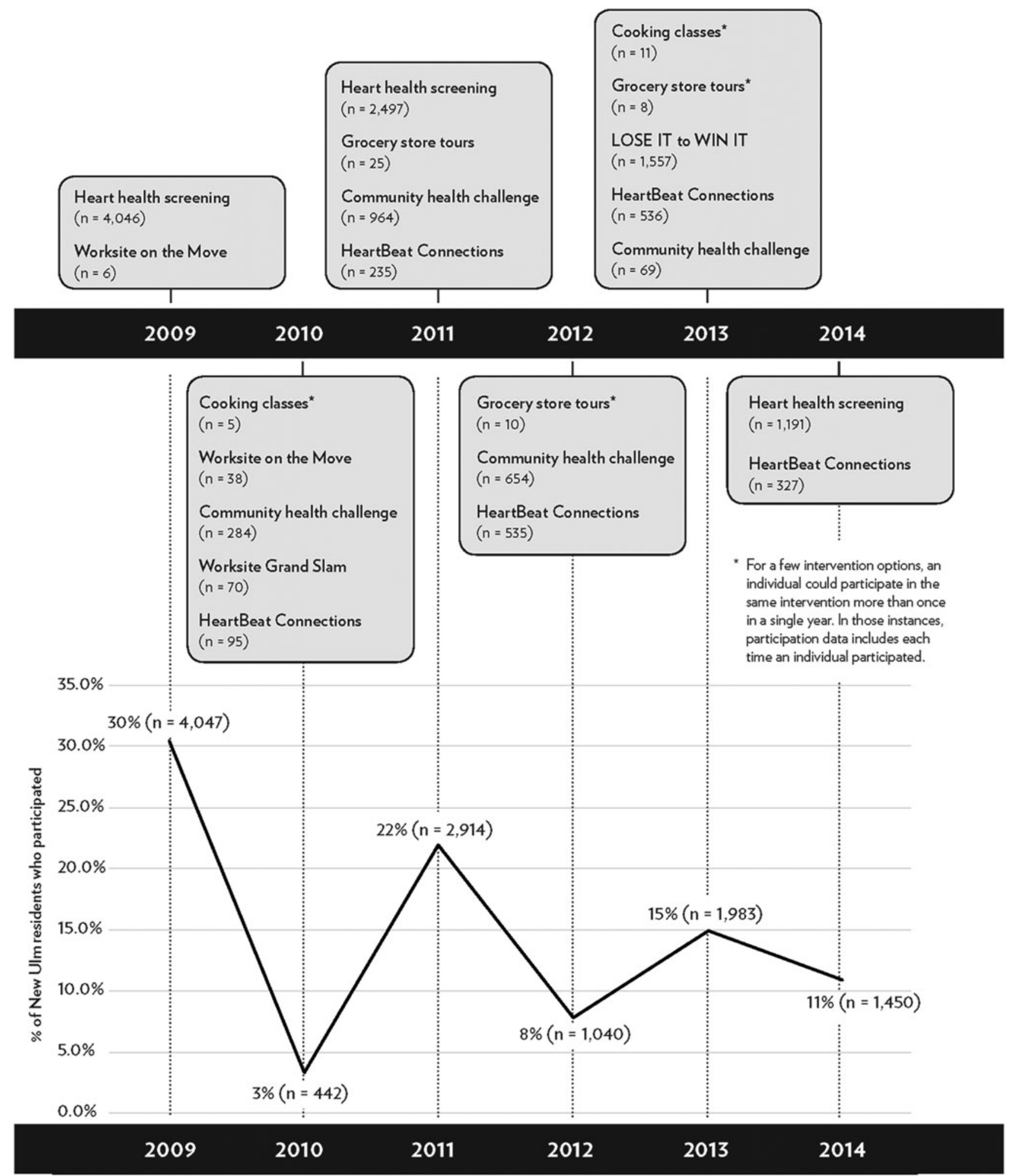

FIG. 2. Time line of Heart of New Ulm interventions with individual participants by intervention.

Participation data. Participation data come from multiple sources. The primary source is a Customer Relationship Management (CRM) database used to track participation. CRM software was preloaded with data from the EHR for adult patients of NUMC with visits from 2008-2009 (ie, name, address, date of birth, sex, patient ID). As participants registered for interventions, name, date of birth, and address were collected as part of the registration process so that an individual's participation record could be linked with their respective record in the CRM system, allowing 
for documentation across multiple interventions. Intervention registration occurred via the HONU website, through worksites, or via onsite registration at the event. Tracking registration was either electronically or manually entered into the CRM system. If an individual was on a registration $\log$ but was not found in the CRM system from the preloaded data, a new ID was created for that person to add to the CRM. Some intervention participation data stored outside the CRM system for screenings or phone coaching (documented in the EHR) were merged with CRM data via the patient identifier to provide a comprehensive data set of intervention participation.

Intervention participation measures created for this analysis include whether an individual participated in any intervention, if they participated in $>1$, and the total number (and by year). Nonparticipants are defined as anyone whose information was in the EHR but who did not appear in any program enrollment data.

\section{Sample inclusion}

Although participation in HONU interventions was open to adults living outside of the HONU priority zip code, analysis was limited to those who resided within the zip code in order to provide participation estimates for the priority community. To compare participants vs. nonparticipants on several health metrics, a data set that linked EHR and program participation data was used (thus participants without an available EHR record for that time period were excluded). This linking process found that $89 \%$ of participants from the priority zip had data available in the EHR (5163 out of 5795).

\section{Analysis}

Descriptive analyses using frequency counts and means were conducted to document participation patterns by intervention. US Census (2010) population estimates of the adult population were used to ascertain the proportions of adult residents of the 56073 zip code participating in HONU in- terventions each year. Comparisons of participants and nonparticipants, as well as participants in different types of interventions, were conducted using $\chi^{2}$ and $t$ tests. Multivariable logistic regression was used to identify determinants of intervention participation. All analyses were conducted using Stata version 15 (StataCorp LLC, College Station, TX).

\section{Results}

\section{Participation patterns}

A total of 7836 unique individuals participated in any of the $20 \mathrm{HONU}$ interventions that tracked enrollment. Of these, 5795 participants were residents of the HONU zip code, which represents approximately $44 \%$ of the adult residents (Table 2). There were 4195 participants in the priority age $40-79$ range at baseline, which is $53 \%$ of the 7855 residents in this age group. Heart health screenings were the intervention with the most participants, with $37 \%$ of adult residents (and $47 \%$ of residents age 40-79) attending at least 1 heart health screening event. The 2009 heart health screenings had the highest attendance of any intervention with more than 4000 participants from the target zip code. Subsequent screenings yielded fewer residents participating in 2011 and 2014 (Table 2).

LOSE IT to WIN IT, ${ }^{30}$ the year-long weight management challenge, was the intervention with the second highest engagement level with $12 \%$ of community adults enrolling. Community health challenges (CHCs) had the third highest engagement level with $10 \%$ of adult residents participating in at least $1 \mathrm{CHC}$. As shown in Figure 2, enrollment in CHCs varied from year to year. HeartBeat Connections, an "invitation-only" intervention that proactively identified eligible patients at high cardiometabolic risk using EHR data and contacted those individuals directly, had the fourth highest participation with $6 \%$ of all adult residents (Table 2). ${ }^{27,31}$ Grocery store tours, cooking classes, and some of the worksite interventions attracted relatively few participants.

Table 2. Intervention Participants (Ages $\geq 18$ Years) for the Heart of New Ulm Project from 2009-2014

\begin{tabular}{|c|c|c|c|c|c|c|c|c|c|}
\hline & $\begin{array}{l}\text { Total unique } \\
\text { participants } \\
\text { (all years) }\end{array}$ & $\begin{array}{l}\text { Percent of } \\
\text { adults in } \\
\text { community }\end{array}$ & $\begin{array}{l}\text { Percent of } \\
\text { adults ages } 40-79 \\
\text { in the community }\end{array}$ & 2009 & 2010 & 2011 & 2012 & 2013 & 2014 \\
\hline & $n$ & $\%$ & $\%$ & $n$ & $n$ & $n$ & $n$ & $n$ & $n$ \\
\hline Any HONU intervention & 5795 & $43.6 \%$ & $53.4 \%$ & 4047 & 442 & 2914 & 1040 & 1983 & 1450 \\
\hline Heart health screening & 4887 & $36.8 \%$ & $46.6 \%$ & 4046 & - & 2497 & - & - & 1191 \\
\hline LOSE IT to WIN IT & 1557 & $11.7 \%$ & $14.0 \%$ & - & - & - & - & 1557 & - \\
\hline Community health challenge ${ }^{a}$ & 1278 & $9.6 \%$ & $11.9 \%$ & - & 284 & 964 & 654 & 69 & - \\
\hline HeartBeat Connections & 841 & $6.3 \%$ & $10.2 \%$ & - & 95 & 235 & 535 & 536 & 327 \\
\hline Grocery store tour ${ }^{\mathrm{a}}$ & 41 & $0.3 \%$ & $0.4 \%$ & - & - & 25 & 10 & 9 & - \\
\hline Cooking class ${ }^{\mathrm{a}}$ & 16 & $0.1 \%$ & $0.2 \%$ & - & 6 & - & - & 20 & - \\
\hline $\begin{array}{l}\text { Worksite behavior } \\
\text { change program }\end{array}$ & 103 & $0.8 \%$ & $0.9 \%$ & 6 & 108 & - & - & - & - \\
\hline
\end{tabular}

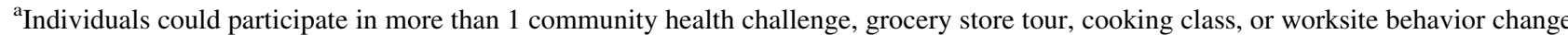
program in a single year. Data shown for each year may double-count an individual if he/she did participate in 2 of these programs in a year. The first column contains only unduplicated individuals.

${ }^{\mathrm{b}}$ Calculated using unique individual adult participants shown and the denominator of 13,290 adult residents in the zip code according to Census data.

${ }^{\mathrm{c} C a l c u l a t e d}$ using unique individual participants ages 40-79 (not shown) and the denominator of 7855 residents ages 40-79 in the zip code according to Census data.

HONU, Heart of New Ulm.
} 
Among all participants, $70 \%$ first participated in HONU during 2009 and 15\% first participated in 2011. Among all HONU intervention participants, about half (48\%) participated in 1 intervention, $23 \%$ participated in 2 interventions, $15 \%$ in 3 interventions, $11 \%$ participated in $4-5$ interventions, and 4\% participated in 6-14 interventions. The average number of interventions per participant was 2.1. About half of participants $(51 \%)$ only participated in heart health screening events, while $33 \%$ participated in a heart health screening plus another type of event, and $15 \%$ participated only in interventions other than heart health screenings (data not shown). Annual participation rates (Figure 2), calculated as a proportion of the community participating each year, ranged from $30 \%$ in 2009 to $11 \%$ in 2014.

\section{Participants vs. nonparticipants}

EHR data were available for 10,829 New Ulm adult residents (ages $\geq 18$ years) from 2008-2009. Of those, 5163 were participants and 5666 were nonparticipants. Compared to nonparticipants, HONU participants in the univariate models (not shown) were significantly older and a higher proportion were female, married, overweight or obese, and had high cholesterol. Participants also had a lower prevalence of smoking and diabetes than nonparticipants. There was no difference between participants and nonparticipants with regard to blood pressure.

Multivariable modeling has similar findings (Table 3). Smokers and individuals with diabetes were less likely to participate. After adjusting for age and sex, overweight or obese residents were more likely to participate (OR 1.20) than those with a BMI $<25$. Women were 1.4 times more likely to participate than men after adjustment for other covariates. Residents ages 40-59 were approximately 3 times more likely to participate than those 18-29 year olds. Those with high cholesterol or missing cholesterol values at baseline were more likely to participate than those with controlled cholesterol.

\section{Discussion}

HONU is the first community-based CVD prevention initiative to track and report unduplicated, individual-level participation data for a wide variety of interventions offered to adult community residents. HONU engaged approximately half of all adults in the entire community in some form of CVD prevention programming. Most program participants $(63 \%)$ engaged in 1 or 2 individual-level HONU interventions. The interventions with the highest number of participants were free heart health screenings (1-time event), a year-long weight loss challenge, short-term (6- to 8-week)

Table 3. Multivariate Logistic Regression Predicting Heart of New Ulm Intervention PARTICIPATION, 2009-2014 $(N=10,829)$

\begin{tabular}{|c|c|c|c|c|}
\hline & $O R$ & $S E$ & $C I$ & $\mathrm{P}$ value \\
\hline \multicolumn{5}{|l|}{ Age category (years) } \\
\hline $18-29$ & Reference & & & \\
\hline $30-39$ & 1.70 & 0.155 & $(1.42-3.03)$ & 0.000 \\
\hline $40-49$ & 2.94 & 0.262 & $(2.47-3.50)$ & 0.000 \\
\hline $50-59$ & 3.20 & 0.269 & $(2.71-3.77)$ & 0.000 \\
\hline $60-69$ & 2.83 & 0.256 & $(2.37-3.38)$ & 0.000 \\
\hline$\geq 70$ & 1.44 & 0.121 & $(1.23-1.70)$ & 0.000 \\
\hline \multicolumn{5}{|l|}{ Sex } \\
\hline Male & Reference & & & \\
\hline Female & 1.38 & 0.062 & $(1.26-1.50)$ & 0.000 \\
\hline \multicolumn{5}{|l|}{ Marital status } \\
\hline Married/equivalent & Reference & & & \\
\hline Single/equivalent & 0.52 & 0.024 & $(0.47-0.57)$ & 0.000 \\
\hline \multicolumn{5}{|l|}{ Diabetes } \\
\hline No & Reference & & & \\
\hline Yes & 0.52 & 0.047 & $(0.44-0.62)$ & 0.000 \\
\hline \multicolumn{5}{|l|}{ Smoking status } \\
\hline Former/never smoker & Reference & & & \\
\hline Current smoker & 0.42 & 0.028 & $(0.37-0.48)$ & 0.000 \\
\hline Missing & 0.41 & 0.026 & $(0.36-0.46)$ & 0.000 \\
\hline \multicolumn{5}{|l|}{ Total cholesterol } \\
\hline At goal & Reference & & & \\
\hline High & 1.19 & 0.088 & $(1.04-1.38)$ & 0.015 \\
\hline Missing & 1.28 & 0.073 & $(1.15-1.43)$ & 0.000 \\
\hline \multicolumn{5}{|c|}{ Obese/overweight $(\mathrm{BMI}>25)$} \\
\hline Normal weight & Reference & & & \\
\hline Obese/overweight & 1.20 & 0.069 & $(1.07-1.34)$ & 0.001 \\
\hline Missing & 0.32 & 0.022 & $(0.28-0.36)$ & 0.000 \\
\hline Intercept & 0.70 & 0.069 & $(0.57-0.85)$ & 0.000 \\
\hline
\end{tabular}

Demographic and health measures are from baseline (2008-2009) EHR data.

BMI, body mass index; CI, confidence interval; EHR, electronic health record; OR, odds ratio; SE, standard error. 
community health challenges (offered 1-2 times/year), and individual phone coaching offered to the select group of residents who were known to be at high CVD risk. Singleencounter education opportunities, such as grocery store tours and cooking classes, had lower enrollment.

Through use of EHR data, which were available for nearly all of the priority community, the HONU evaluation was able to assess differences between participants and nonparticipants, as well as identify which segments of the community were most likely to participate. Several findings provide evidence that HONU was successful at reaching the priority population identified. Specifically, $53 \%$ of residents in the 40-79 age range participated in at least $1 \mathrm{HONU}$ program. Additionally, models demonstrated that residents choosing to participate in HONU programs had a higher prevalence of overweight/obesity and high cholesterol than nonparticipants. These findings are an indication of reaching the intended audience (ie, those who could benefit from lifestyle risk factor reduction or pre disease intervention).

However, HONU programs were less likely to engage smokers or residents with diabetes, which represents a missed opportunity for those with at least 1 major CVD risk factor. Lastly, the finding that a higher proportion of women (than men) participated suggests that future efforts consider modifications to recruitment efforts and/or program offerings. Qualitative interviews may be a helpful strategy to discover ways to engage men, smokers, and individuals with diabetes. These data also underscore the importance of working at all levels of the social-ecological model to impact those not reached through individual-level interventions.

Few community-based initiatives are known to have documented individual-level engagement in community interventions, with tracking at the unduplicated resident level to provide rates of community participation. The availability of EHR data to represent the entire community offered the HONU project advantages that other community-based initiatives did not have to assess community reach. HONU interventions engaged an estimated $44 \%$ of unique adult residents and $53 \%$ of residents within the priority age range of 40-79.

To put this into context, the Minnesota Heart Health Program (MHHP) estimated that $60 \%$ of residents age $25-74$ participated in a screening and education program, and $30 \%$ participated in a face-to-face intervention program across their 3 intervention communities. ${ }^{34}$ Although MHHP provided some counts of participants in specific types of programs such as smoking cessation, ${ }^{35}$ no comprehensive reporting of all programs offered was provided. The Pawtucket Heart Health Program had similar findings of reach, as $59 \%$ of the population participated in $\geq 1$ project interventions. ${ }^{36,37}$ Documentation of the efforts of a long-term CVD prevention project in Franklin County reported more than 150,000 health education encounters during the 40-year intervention period, but unfortunately does not document unduplicated participants to assess community reach. ${ }^{38}$ Similarly, the Heart to Heart Project, a Centers for Disease Control and Prevention-funded community-based prevention program in South Carolina, reports counts of 31,850 program participants. However, their counts do not reflect unique participants, limiting the ability to assess proportion of the community engaged. ${ }^{39}$

HONU's highest participation in heart health screenings, reaching $37 \%$ of adult residents (and $47 \%$ of those age 40-79), is similar to findings from prior community CVD prevention projects. $^{34}$ The Pawtucket Heart Health program reported that nearly all of their participants received only screening services $(55 \%)$. ${ }^{37}$ Other CVD projects reporting on participation did not offer heart health screening events 38,39 and thus cannot be compared for this activity.

HONU heart health screenings were the first intervention offered to the community and were held at 3 intervals throughout the project's duration, with the highest enrollment during the first year. HONU's first year served as an opportunity to provide a baseline "community diagnosis," and as such, screenings were promoted heavily in the beginning to attract participants. Later screenings were not promoted as much given more limited project and staffing resources. More than 100 screening events were held throughout the community (compared to 66 in 2011 and 24 in 2014 , plus additional opportunities to participate via a wellness visit). Another factor that likely influenced higher participation at baseline was the novelty of screenings, with less enthusiasm in subsequent years. Anecdotally, some individuals reported a desire for more time to make lifestyle changes before being screened again and more opportunities to participate in similar screenings through their employer.

Prior community-based CVD prevention initiatives demonstrated limited impact on health outcomes. ${ }^{36}$ One explanation for this is limited intervention delivery such as inadequate penetration into the community (and at an insufficient intensity level) necessary to bring about sustained behavior change. Programs often reported highest penetration for public information and screening, with less penetration for more intense interventions. ${ }^{36}$ Current findings are consistent with this in terms of screenings rates. However, HONU also was able to engage a substantial proportion of the community in higher intensity interventions, such as $12 \%$ of the adult population in a year-long weight loss challenge, $10 \%$ of the population in 6- to 8-week challenges, and $6 \%$ of the population in a long-term phone coaching program. As an invitation-only program, HeartBeat Connections engaged $30 \%$ of patients who were eligible to participate. This substantial community reach and engagement in longer term interventions likely contributed to the demonstrated positive health outcomes of HONU. ${ }^{24}$

The HONU interventions that yielded the highest engagement were those that (1) had significant staffing and funding resources dedicated to recruiting participants and (2) provided ample opportunities for registration. The role of intensive recruitment is an important consideration for future projects that aim to engage a high proportion of a community. Partnerships with worksites to engage employees is a strategy that may benefit future initiatives. Although some worksitespecific interventions had low enrollment numbers (eg, Worksite on the Move, Worksite Grand Slam), the interventions with some of the highest enrollment included worksite-based recruitment and implementation partnerships in addition to robust community-wide promotion.

Heart health screenings, LOSE IT to WIN IT, and some of the community health challenges were conducted in partnership with larger employers so that residents could participate on their own or within the context of their workplace. On-site recruitment and implementation activities, depending on the intervention, were staffed by HONU employees, including a HONU team member devoted to worksite partnerships. Tailored communication strategies 
were provided to employers to help bolster employee participation. The close partnership between HONU and worksites, and specifically dedicated staff support, likely was a major factor in the high enrollment in specific HONU interventions. It also is important to note that HONU relied on individual worksite staff to promote HONU interventions within their worksites. As such, participation in HONU interventions varied by which worksites chose to participate and how much their staff promoted the intervention.

As part of a community health needs assessment sent to a random sample of households in New Ulm, 37\% of respondents indicated that they heard about one of the project's initiatives through their worksite, making worksites a more common source of information about interventions than project newsletters, friends and family, and media coverage. Given that full-time employees spend the majority of their time at work, engaging worksites as a recruitment and delivery partner for community programming makes sense. At the same time, having a staff person dedicated to maintaining relationships with worksites and conducting onsite enrollment or program delivery may be a limiting factor for other community-based programs.

\section{Implications for other rural communities}

Future community-based interventions could improve participation tracking by taking advantage of newer technologies available to report individual-level participation (eg, key fob, app-based trackers). Use of such technologies could enable more complete documentation of participation in all individual-level programs or events in a community, and thus have the ability to provide more complete documentation of intensity of participation. HONU also utilized a robust communications strategy from the outset - blanketing the community with messages and social marketing efforts to reinforce individual-level behavior change. A high level of project awareness has been instrumental to HONU's success, and a notable consideration for future populationbased initiatives.

In the context of HONU as a research project, the authors recognize that other communities likely will not have the same level of resources that were available to implement individual programming efforts. Thus it is imperative to create partnerships with community resources. For example, partnering with local worksites that have dedicated worksite wellness staff would be instrumental to ensure registration/participation at those sites for community programming and/or screening efforts (and is likely more feasible than program staff conducting this work). HONU's broader partnership with the local health care system, and in particular being able to reuse EHR data for program evaluations, was instrumental in tracking health outcomes.

\section{Strengths and limitations}

This evaluation design has several strengths and limitations. One of the major strengths of this is the use of an EHR with data representative of the population living in the priority community. Such data enabled a rigorous comparison of participants and nonparticipants, not previously provided by prior community-based program evaluations. Secondly, the documentation of which specific interventions individual residents participated in provides a level of detail also not documented in other community-based intervention evaluations. A weakness of this evaluation is possible undercounting related to inconsistent enrollment practices for some programs (cooking classes and grocery store tours) or lack of data for programs in which the enrollment was not through the HONU project directly, but sponsored by HONU (such as run/walk events or neighborhood health events).

It is important to note that the data in this paper reflect individual-level initiative participation and are not reflective of the full HONU project delivery or the ways in which the HONU project may have impacted individual residents. HONU sought to create a culture of wellness and enhance the environmental and social context in which individuals in New Ulm were living to be supportive of healthy behaviors. As such, during the 6 years documented here, HONU implemented several other social and environmental efforts that could have impacted individual residents (Figure 1). Although individual-level initiatives focused on education and coaching to make positive behavior changes, there also was a broader effort to improve the food and built environments by creating increased availability of healthful foods and physical activity opportunities. Collectively, HONU programming and policy efforts may have created opportunities for individuals to make healthier choices and be a part of a social movement around health and wellness.

\section{Conclusion}

In order to effectively reduce CVD at a population level, community-based CVD prevention programs must improve behavioral risk factors and reach a large enough fraction of the target population. Although social, environmental, and policy strategies are essential to create a supportive environment, individual programming and interventions also are instrumental to initiate behavior changes. The HONU project provides an example of such a program implemented through a partnership with health care and community organizations, which allowed for use of EHR data to identify the priority population and evaluate reach and engagement.

Although somewhat biased toward middle-aged females and nonsmokers without diabetes, the HONU project demonstrates that relatively high levels of community engagement can be attained by offering a mix of short-term (eg, heart health screening) and focused longer term programs. Future research should continue to explore how creative methods can engage high proportions of community residents to participate in mixed-intensity programs designed to improve their health.

\section{Acknowledgments}

The authors gratefully acknowledge the Heart of New Ulm Steering Committee and the residents of New Ulm who support and participate in the program. We also acknowledge Kevin Graham, MD, whose vision contributed to the conceptualization and development of the HONU Project.

\section{Author Disclosure Statement}

The authors declare that there are no conflicts of interest. 


\section{Funding Information}

The Heart of New Ulm Project described in this paper was funded primarily by Allina Health during the period studied in this manuscript, with some additional funding from grants from the United Health Foundation, a Centers for Disease Control and Prevention Community Transformational grant, and the US Department of Agriculture Farmers Market Program. No extramural funding was used to support the research work of this manuscript.

\section{References}

1. Go AS, Mozaffarian D, Roger VL, et al. Heart disease and stroke statistics-2014 update: a report from the American Heart Association. Circulation 2014;129:e28-e292.

2. Knudson A, Meit M, Popat S. Rural-Urban Disparities in Heart Disease, Policy Brief from the Rural Health Reform Policy Research Center. October 2014. https://ruralhealth .und.edu/projects/health-reform-policy-research-center/pdf/ rural-urban-disparities-in-heart-disease-oct-2014.pdf Accessed October 1, 2019.

3. Moy E, Garcia MC, Bastian B, et al. Leading causes of death in nonmetropolitan and metropolitan areas-United States, 1999-2014. MMWR Surveill Summ 2017;66:1-8.

4. Yusuf S, Hawken S, Ounpuu S, et al. Effect of potentially modifiable risk factors associated with myocardial infarction in 52 countries (the INTERHEART study): casecontrol study. Lancet 2004;364:937-952.

5. McGovern L, Miller G, Hughes-Cromwick P. Health Policy Brief: The Relative Contribution of Multiple Determinants to Health Outcomes. 2014. https://www.healthaffairs.org/ do/10.1377/hpb20140821.404487/full/healthpolicybrief_ 123.pdf Accessed October 1, 2019.

6. Douthit N, Kiv S, Dwolatzky T, Biswas S. Exposing some important barriers to health care access in the rural USA. Public Health 2015;129:611-620.

7. Quarells RC, Liu J, Davis SK. Social determinants of cardiovascular disease risk factor presence among rural and urban black and white men. J Mens Health 2012;9:120126.

8. Mudd-Martin G, Biddle MJ, Chung ML, et al. Rural Appalachian perspectives on heart health: social ecological contexts. Am J Health Behav 2014;38:134-143.

9. Smith C, Morton LW. Rural food deserts: low-income perspectives on food access in Minnesota and Iowa. J Nutr Educ Behav 2009;41:176-187.

10. Shaw KM, Theis KA, Self-Brown S, Roblin DW, Barker L. Chronic disease disparities by county economic status and metropolitan classification, Behavioral Risk Factor Surveillance System, 2013. Prev Chronic Dis 2016;13:E119.

11. Pearson TA, Bazzarre TL, Daniels SR, et al. American Heart Association guide for improving cardiovascular health at the community level: a statement for public health practitioners, healthcare providers, and health policy makers from the American Heart Association Expert Panel on Population and Prevention Science. Circulation 2003;107: 645-651.

12. Pearson TA, Palaniappan LP, Artinian NT, et al. American Heart Association guide for improving cardiovascular health at the community level, 2013 update: a scientific statement for public health practitioners, healthcare providers, and health policy makers. Circulation 2013;127: 1730-1753.
13. Mamudu HM, Paul TK, Wang L, et al. The effects of multiple coronary artery disease risk factors on subclinical atherosclerosis in a rural population in the United States. Prev Med 2016;88:140-146.

14. Bodenheimer T, Sinsky C. From triple to quadruple aim: care of the patient requires care of the provider. Ann Fam Med 2014;12:573-576.

15. Berwick DM, Nolan TW, Whittington J. The triple aim: care, health, and cost. Health Aff (Millwood) 2008;27:759 769.

16. Magnan S, Fisher E, Kindig D, et al. Achieving accountability for health and health care. Minn Med 2012;95: 37-39.

17. Austen BioInnovation Institute in Akron. Healthier by design: creating accountable care communities-a framework for engagement and sustainability. Akron $\mathrm{OH}$ : Austen BioInnovation Institute in Akron, 2012.

18. Mozaffarian D, Benjamin EJ, Go AS, et al. Heart disease and stroke statistics-2015 update: a report from the American Heart Association. Circulation 2015;131:e29e322.

19. Mozaffarian D, Afshin A, Benowitz NL, et al. Population approaches to improve diet, physical activity, and smoking habits: a scientific statement from the American Heart Association. Circulation 2012;126:1514-1563.

20. Bergeron CD, Foster C, Friedman DB, Tanner A, Kim SH. Clinical trial recruitment in rural South Carolina: a comparison of investigators' perceptions and potential participant eligibility. Rural Remote Health 2013;13:2567.

21. Young L, Montgomery M, Barnason S, Schmidt C, Do V. A conceptual framework for barriers to the recruitment and retention of rural CVD participants in behavior intervention trials. GSTF J Nurs Health Care 2015;2:19-24.

22. Boucher JL, Pereira RF, Graham KJ, Pettingill RR, Toscano JV, Henry TD. The Heart of New Ulm: a vision for the future. J Cardiovasc Transl Res 2008;1:310-316.

23. VanWormer JJ, Johnson PJ, Pereira RF, et al. The Heart of New Ulm Project: using community-based cardiometabolic risk factor screenings in a rural population health improvement initiative. Popul Health Manag 2012;15:135143.

24. Sidebottom AC, Sillah A, Vock DM, et al. Assessing the impact of the heart of New Ulm Project on cardiovascular disease risk factors: a population-based program to reduce cardiovascular disease. Prev Med 2018;112:216-221.

25. American Fact Finder. 2010 Census and 2013-2017 American Community Survey estimates. https://factfinder .census.gov/faces/nav/jsf/pages/index.xhtml Accessed December 13, 2019 (for geographic area 56073).

26. Sidebottom AC, Johnson PJ, VanWormer JJ, Sillah A, Winden TJ, Boucher JL. Exploring electronic health records as a population health surveillance tool of cardiovascular disease risk factors. Popul Health Manag 2015;18: 79-85.

27. Benson GS, Sidebottom A, VanWormer JJ, Boucher JL, Stephens C, Krikava J. HeartBeat connections: a rural community of solution for cardiovascular health. J Am Board Fam Med 2013;26:299-310.

28. Sillah A, Sidebottom AC, Boucher JL, Pereira R, VanWormer JJ. Program participation and blood pressure improvement in the Heart of New Ulm Project, Minnesota, 2009-2011. Prev Chronic Dis 2014;11:E48.

29. Sidebottom AC, Sillah A, Miedema MD, et al. Changes in cardiovascular risk factors after 5 years of implementation 
of a population-based program to reduce cardiovascular disease: the Heart of New Ulm Project. Am Heart J 2016; 175:66-76.

30. VanWormer JJ, Pereira RF, Sillah A, et al. Adult weight management across the community: population-level impact of the LOSE IT to WIN IT challenge. Obes Sci Pract 2018;4:119-128.

31. Benson GA, Sidebottom AC, Sillah A, et al. Reach and effectiveness of the HeartBeat Connections telemedicine pilot program. J Telemed Telecare 2018;24:216-223.

32. McLeroy KR, Bibeau D, Steckler A, Glanz K. An ecological perspective on health promotion programs. Health Educ Q 1988;15:351-377.

33. Minneapolis Heart Institute Foundation. Getting to the Heart of It: The Power of True Engagement for Population Health. 2017. https://www.academyhealth.org/sites/default/ files/AcademyHealthEngagementGuideFINAL.pdf Accessed October 1, 2019.

34. Luepker RV, Murray DM, Jacobs DR Jr., et al. Community education for cardiovascular disease prevention: risk factor changes in the Minnesota Heart Health Program. Am J Public Health 1994;84:1383-1393.

35. Lando HA, Pechacek TF, Pirie PL, et al. Changes in adult cigarette smoking in the Minnesota Heart Health Program. Am J Public Health 1995;85:201-208.
36. Merzel C, D'Afflitti J. Reconsidering community-based health promotion: promise, performance, and potential. Am J Public Health 2003;93:557-574.

37. Elder JP, McGraw SA, Abrams DB, et al. Organizational and community approaches to community-wide prevention of heart disease: the first two years of the Pawtucket Heart Health Program. Prev Med 1986;15:107-117.

38. Record NB, Onion DK, Prior RE, et al. Community-wide cardiovascular disease prevention programs and health outcomes in a rural county, 1970-2010. JAMA 2015;313: $147-155$.

39. Goodman RM, Wheeler FC, Lee PR. Evaluation of the heart to heart project: lessons from a community-based chronic disease prevention project. Am J Health Promot 1995;9:443-455.

Address correspondence to: Abbey C. Sidebottom, MPH, PhD Care Delivery Research Allina Health 800 East 28th Street, MR 15521 Minneapolis, MN 55407-3799 USA

E-mail: abbey.sidebottom@allina.com 